\title{
PELATIHAN PENYUSUNAN RENCANA EVAKUASI BENCANA DI SD MUHAMMADIYAH SE-KECAMATAN BANGUNTAPAN, BANTUL, DIY
}

\author{
Oleh: \\ Oktomi Wijaya, Khoiriyah Isni \\ Dosen Fakultas Kesehatan Masyarakat, Universitas Ahmad Dahlan
}

\section{Ringkasan}

Tingginya risiko bencana yang ada di Provinsi Yogyakarta khususnya Kabupaten Bantul, maka mutlak diperlukan suatu upaya pengurangan risiko bencana, terutama di sekolah yang merupakan komunitas anak-anak sebagai kelompok rentan. Sekolah dasar tentu harus mendapatkan perhatian yang lebih dikarenakan anak-anak SD memiliki kerentanan yang lebih tinggi. Oleh karena itu, dibutuhkan suatu perhatian khusus kepada siswa sekolah dasar terkait dengan kemampuan menghadapi bencana. Upaya kesiapsiagaan sekolah dapat dimulai dengan analisis risiko bencana di sekolah, pembuatan prosedur kedaruratan bencana dan berlatih menyelamatkan diri saat terjadi bencana.

Metode yang digunakan dalam pelatihan ini antara lain: (1) pendidikan masyarakat atau penyuluhan, (2) pelatihan atau praktik, (3) simulasi. Tujuannya adalah peserta mendapatkan keterampilan tidak hanya berdasarkan pelatihan atau praktik, namun juga secara teori atau pengetahuan.

Output kegiatan pelatihan ini antara lain: (1) peningkatan pengetahuan siswa dan guru sekolah dasar terkait perencanaan evakuasi bencana, (2) peningkatan keterampilan siswa dan guru sekolah dasar dalam mengevakuasi ketika terjadi bencana, (3) diseminasi hasil kegiatan berupa produk publikasi dan modul pelatihan. Outcome yang diperoleh dari kegiatan ini adalah pembuatan peta dan jalur evakuasi yang dicetak ukuran besar dan ditempel di dinding sekolah, sehingga dapat diketahui dan dipahami setiap warga sekolah.

Secara umum, kegiatan pelatihan efektif dalam meningkatkan pengetahuan dan keterampilan siswa dan guru sekolah dasar mengenai perencanaan evakuasi bencana di sekolah. Disamping itu, tersusunnya peta, jalur, dan rambu evakuasi bencana sesuai situasi dan kondisi sekolah masingmasing.

Kata kunci : evakuasi bencana, SD Muhammadiyah, Kecamatan Banguntapan.

\begin{abstract}
Bantul District, special region of Yogyakarta has the high risk for disasters. In order to protect the community from the impact of disaster, the government should conduct disaster risk reduction program, especially in the schools where students are high risk group in disaster. Therefore, it's needed to improve the students ability to face the disaster. The school preparedness for disaster can be initiated by starting the risk analysis, making procedure for disaster, and training to conduct self evacuation during the disaster.

Methods used in this training were: 1) Community education 2) Training, 3) Simulation. The objective of this training was to increase the community ability to respond the disaster. Output of this training was: 1) to increase the knowledge of the student and teacher regarding to disaster evacuation plan, 2) to improve the students and teachers ability in evacuation in disaster situation, 3) Dissemination of publication and training module. Outcome of this training was hazard mapping and evacuation route that displayed in the schools, so that it can be understood by the school community.

The training was effective to increase the students and teacher knowledge and capability related to disaster evacuation plan. In addition, the school has created hazard mapping, evacuation route, and evacuation sign based on the existing condition in the school.
\end{abstract}

Key Words: Disaster, Evacuation Plan, Muhammadiyah Elemntaruy School, Banguntapan 


\section{A. PENDAhULUAN}

Indonesia mengalami beberapa kejadian bencana besar yang banyak menimbulkan korban jiwa dan kerugian, yakni: 1). bencana gempa bumi dan tsunami Aceh pada bulan Desember 2004 yang mengakibatkan korban meninggal sebanyak 165.708 orang dan kerugian sebesar Rp 48 trilyun; 2). gempa bumi Yogyakarta dan Jawa Tengah yang terjadi pada bulan Mei 2006 yang mengakibatkan korban meninggal sebanyak 5.716 orang, rumah rusak sebanyak 156.162 dan kerugian ditaksir sebesar Rp 29,1 trilyun; 3). tsunami Pangandaran yang terjadi pada bulan Juli 2006 yang mengakibatkan korban meninggal sebanyak 649 orang, sebanyak 1.908 rumah rusak dan kerugian ditaksir mencapai Rp 138 milyar; 4). banjir Jakarta, bulan Februari 2007 yang mengakibatkan 145.742 rumah tergenang dan kerugian Rp 967 milyar (Bappenas, 2007).

Provinsi Daerah Istimewa Yogyakarta memiliki kerentanan terhadap berbagai ancaman bencana alam. Ancaman terbesar antara lain gempa bumi dan letusan gunung berapi. Hal ini tidak terlepas dari posisi geologis Yogyakarta yang berada di daerah seismik aktif. Selain itu, gunung merapi merupakan salah satu gunung api teraktif di dunia dengan periode ulang letusan 4 tahun. Bencana terbesar yang pernah tercatat dalam sejarah antara lain adalah gempa bumi Yogyakarta 27 Mei tahun 2006 dan Erupsi Gunung merapi Tahun 2010. Ancaman bencana lain adalah angin puting beliung, kekeringan, tanah longsor dan tsunami. (Karnawati dkk, 2009).

Bencana tidak hanya menyebabkan korban jiwa, kerusakan dan kerugian saja, akan tetapi juga mengakibatkan terganggunya layanan pendidikan. Banyak bangunan sekolah yang berada pada kawasan rawan bencana tidak dapat digunakan lagi dan warga sekolah terpaksa harus melaksanakan proses belajar mengajar di tenda-tenda atau menggunakan gedung sekolah lain. Tidak sedikit juga sekolah yang tidak dapat melaksanakan kegiatan belajar mengajar karena belum memiliki standar operasional prosedur sekolah darurat.

Terkait dengan pendidikan dan penyadaran publik mengenai pengurangan risiko bencana, selama beberapa tahun ini, beberapa institusi dan organisasi seperti lembaga Pemerintah, LSM, dan institusi pendidikan di tingkat nasional maupun daerah telah melakukan berbagai upaya dalam pendidikan kebencanaan termasuk memasukkan materi kebencanaan ke dalam muatan lokal, pelatihan untuk guru, kampanye dan advokasi. Namun demikian kegiatan-kegiatan tersebut belum terkoordinasi dengan baik dan belum terintegrasi dalam satu kerangka yang dapat disepakati bersama.

Rendahnya kesiapsiagaan sekolah dalam menghadapi bencana akan meningkatkan risiko kerugian akibat bencana. Kesiapsiagaan warga sekolah yang masih rendah dapat disebabkan oleh masih rendahnya pemahaman warga sekolah terkait bencana. Agar kesiapsiagaan sekolah dapat meningkat, warga sekolah harus memahami ancaman bencana yang ada di sekolah. Selanjutnya warga sekolah juga harus memahami prosedur tanggap darurat bencana dan terampil dalam penyelamatan diri saat terjadi bencana.

Sekolah Muhammadiyah merupakan salah satu Amal Usaha Muhammadiyah (AUM) yang menyelenggarakan pendidikan di berbagai tingkatan mulai dari Pra sekolah sampai dengan perguruan tinggi. Pengetahuan dan keterampilan bencana ini seyogyanya diajarkan sejak dini. Harapannya anak-anak telah tertanam sikap sigap bencana sejak kecil. 
Dalam konteks bencana, siswa sekolah dasar memiliki kerentanan yang tinggi dalam bencana terkait kemampuan mereka dalam menghadapi bencana.

Kabupaten Bantul memiliki risiko tinggi terhadap bencana. Siswa Sekolah dasar dengan keterbatasan kemampuan bertindak sehingga dikategorikan memiliki kerentanan bencana yang tinggi. Siswa membutuhkan perhatian khusus kepada siswa sekolah dasar terkait dengan kemampuan menghadapi bencana. Oleh karena itu, diperlukan suatu pelatihan untuk meningkatkan kesiapsiagaan warga Sekolah Dasar Muhammadiyah seKecamatan Banguntapan dalam menghadapi bencana serta mewujudkan sekolah/madrasah aman bencana (SMAB).

Sekolah/madrasah aman bencana (SMAB), yaitu Sekolah yang menerapkan standar sarana dan prasarana serta budaya yang mampu melindungi warga sekolah dan lingkungan di sekitarnya dari bahaya bencana (Kementerian Pendidikan dan Kebudayaan, 2017).

Pelaksanaan Sekolah/Madrasah Aman sesuai dengan tujuannya bersifat multisektor dan membutuhkan kerjasama berbagai pihak. Prinsip-prinsip pokok Sekolah/ Madrasah Aman mendasari kerjasama lintas sektor guna mengupayakan sinergisitas dalam mewujudkan Sekolah/Madrasah Aman. Prinsip-prinsip pokok tersebut adalah :

1. Berbasis Pengurangan Risiko Bencana. Sekolah/ Madrasah Aman ditujukan untuk mengurangi risiko bencana dan memastikan kenyamanan dan keamanan proses pembelajaran. Dalam hal ini, selain berkontribusi pada pengurangan risiko bencana geologis, misalnya gempa dan tsunami, pelaksanaan kegiatan Sekolah/Madrasah Aman juga ditujukan untuk mengurangi risiko bencana yang disebabkan oleh kerusakan lingkungan misalnya banjir dan longsor, yang frekuensi kejadiannya semakin meningkat.

2. Inklusif. Penyelenggaran Sekolah/Madrasah Aman secara aktif melibatkan semua warga sekolah termasuk warga sekolah penyandang disabilitas atau berkebutuhan khusus guna memastikan tidak ada pihak yang tertinggal dalam situasi bencana. Dalam hal ini, penyelenggara Sekolah/Madarasah Aman harus memperhatikan perluasan aksesibilitas fisik dan non-fisik untuk memastikan partisipasi aktif warga sekolah penyandang disabilitas.

3. Ramah Anak. Pelaksanaan Sekolah/Madrasah Aman diselenggarakan atas dasar pemenuhan tumbuh kembang dan perlindungan anak serta, memperhatikan kemampuan dan partisipasi aktif anak demi kepentingan terbaik anak. 
Adapun tujuan dari kegiatan pelatihan ini diuraikan sebagai berikut:

1. Warga sekolah memahami definisi bencana dan jenis-jenis bencana

2. Warga sekolah mampu mengenali potensi ancaman bencana di lingkungan sekolah

3. Warga sekolah mampu menyusun rencana evakuasi bencana di sekolah yang dilengkapi Peta Jalur Evakuasi, Rambu Evakuasi, dan Titik Kumpul.

4. Warga sekolah mampu membuat dan memasang Peta Jalur Evakuasi, Rambu Evakuasi, dan Titik Kumpul.

5. Warga sekolah terampil dalam melakukan evakuasi

Apabila ditinjau dari segi manfaat, maka kegiatan pelatihan ini adalah sebagai upaya menanggulangi dan meminimalisir korban bencana alam dengan keterampilan evakuasi di masing-masing SD Muhammadiyah se-Kecamatan Banguntapan melalui pembuatan rencana jalur evakuasi bencana sesuai dengan kebutuhan sekolah masingmasing.

\section{B. METODE PELAKSANAAN}

\section{Metode Pelaksanaan Kegiatan Pengabdian}

Kegiatan Pelatihan Penyusunan Rencana Evakuasi Bencana di SD Muhammadiyah se-Kecamatan Banguntapan, Bantul, DIY dilaksanakan oleh dua orang dosen Fakultas Kesehatan Masyarakat (FKM) Universitas Ahmad Dahlan (UAD) dan dibantu oleh dua orang mahasiswa semester tujuh dari peminatan kesehatan dan keselamatan kerja dan promosi kesehatan. Sasaran dari program ini adalah warga SD Muhammadiyah SeKecamatan Banguntapan yaitu SD Muhammadiyah Bodon, SD Muhammadiyah Kalangan, SD Muhammadiyah Karang Bendo, SD Muhammadiyah Banguntapan, SD Muhammadiyah Karang turi, SD Muhammadiyah Mertosanan. Masing-masing SD Muhammadiyah terdiri dari perwakilan 2-4 siswa SD kelas 4-6 dan 1 orang guru.

Kegiatan ini termasuk penelitian tindakan (Action research) berbentuk pendidikan masyarakat/penyuluhan, pelatihan dan simulasi. Pendidikan masyarakat atau penyuluhan sebagai upaya mengawali proses pemberdayaan dan pelatihan, bertujuan untuk menghasilkan perubahan sudut pandang peserta terhadap bencana, peningkatan pemahaman, kesadaran, kesiapsiagaan, dan kesanggupan dalam menghadapi dan mengevakuasi ketika terjadi bencana di Sekolah. Materi pendidikan masyaratakat atau penyuluhan bermuatan utama terkait kajian Sekolah/madrasah Aman Bencana (SMAB), kajian analisis bencana, risiko bencana di sekolah, dan cara penyusunan rencana evakuasi sekolah. Metode ini bertujuan melakukan transformasi pengetahuan dan kecapkapanaau keterampilan dalam penyusunan rencana evakuasi bencana di sekolah. Hasil yang diperoleh adalah peserta diharapkan memiliki pengetahuan dan kecakapan atau keterampilan mengenai bencana di sekolah.

Pelatihan atau praktek sebagai upaya lanjutan dalam proses pemberdayaan, yang bertujuan untuk meningkatkan kecakapan atau keterampilan siswa dan guru sekolah dasar 
Diterbitkan oleh Lembaga Pengabdian kepada Masyarakat

Universitas Ahmad Dahlan Yogyakarta

dalam penyusunan rencana evakuasi sekolah dan penyusunan prosedur tanggap darurat bencana di skeolah.

Metode simulasi, sebagai upaya akhir mensinergikan antara pengetahuan yang diperoleh mengenai bencana di sekolah melalui proses pendidikan masyarakat atau penyuluhan dengan pelatihan atau praktik. Sehingga hasil yang diperoleh lebih maksimal dengan adanya simulasi. Simulasi yang dilakukan meliputi simulasi evakuasi bencana di sekolahberdasarkan studi kasus yang diberikan oleh fasilitator.

Penyuluha

Kerangka konsep sekolah aman

\section{Pelatihan}

Simulasi

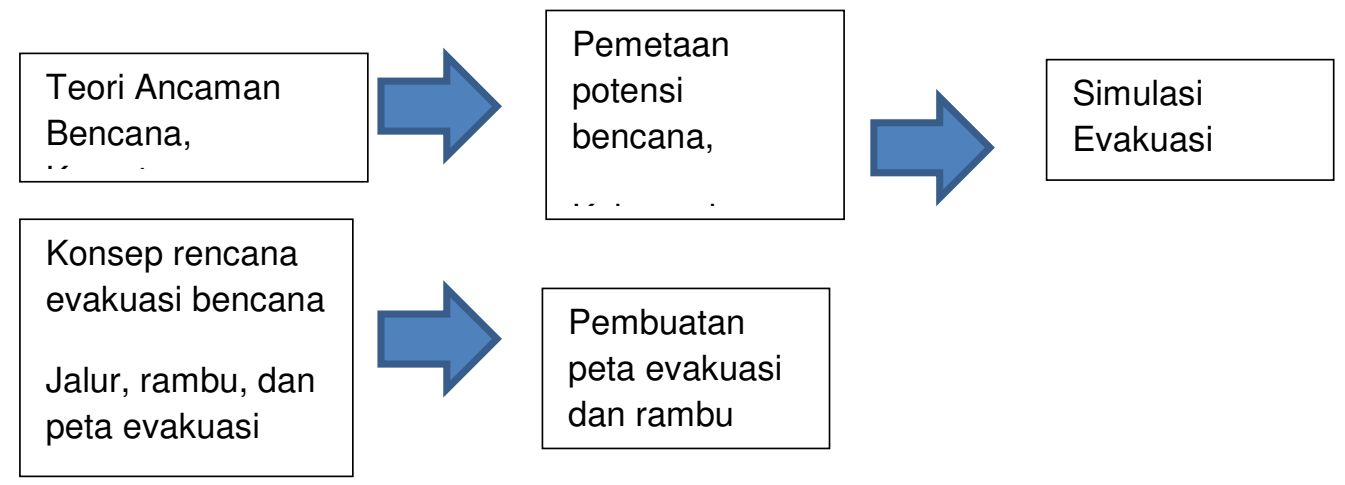

Gambar I. Konsep Pelatihan Penyusunan Rencana Evakuasi Bencana di SD Muhammadiyah Se-Kecamatan Banguntapan, Bantul, DIY

1. Teknik Pengumpulan Data

Pengumpulan data dilakukan melalui teknik wawancara, observasi, dan dokumentasi kegiatan.

2. Teknik Analisis Data

Analisa data dilakukan dengan pendekatan kuantitatif, yaitu mendeskripsikan berupa perbandingan skor rata-rata pengetahuan antara sebelum dan setelah mendapatkan pelatihan penyusunan rencana evakuasi bencana yang dianalisis secara statistic yaitu univariat.

3. Lokasi, Waktu, dan Durasi Kegiatan

Kegiatan ini dilaksanakan selama dua hari yaitu tanggal 23-24 Mei 2017 di ruang laboratorium komputer SD Muhammadiyah Bodon, Banguntapan, Bantul, DIY. Adapun durasi kegiatan diuraikan dalam tabel I sebagai berikut: 
Tabel I. Susunan Kegiatan Pelatihan Penyusunan Rencana Evakuasi Bencana di SD Muhammadiyah se-Kecamatan Banguntapan, Bantul, DIY

\begin{tabular}{|c|c|c|}
\hline Waktu & Kegiatan & Keterangan \\
\hline \multicolumn{3}{|c|}{ Hari I : Selasa, 23 Mei 2017} \\
\hline $08.00-08.15$ & Registrasi peserta & Panitia \\
\hline $08.15-08.30$ & Pembukaan kegiatan pelatihan & Dekan FKM UAD \\
\hline $08.30-08.45$ & Pre Test & Panitia \\
\hline $08.30-10.00$ & $\begin{array}{l}\text { Materi I : } \\
\text { Sekolah Aman Bencana }\end{array}$ & Teori \\
\hline $10.00-12.00$ & $\begin{array}{l}\text { Materi II : } \\
\text { Kajian Analisis Bencana }\end{array}$ & Teori \\
\hline $12.00-12.45$ & Ishoma & \\
\hline $12.45-14.45$ & $\begin{array}{l}\text { Materi III : } \\
\text { Kajian risiko bencana di Sekolah }\end{array}$ & Teori, praktik \\
\hline $14.45-16.00$ & $\begin{array}{l}\text { Materi IV: } \\
\text { Jalur evakuasi, rambu evakuasi, dan peta } \\
\text { evakuasi }\end{array}$ & Teori, praktik \\
\hline \multicolumn{3}{|c|}{ Hari II : Rabu, 24 Mei 2017} \\
\hline $08.00-08.15$ & Registrasi Peserta & Panitia \\
\hline $08.15-09.00$ & Penyusunan rencana evakuasi sekolah & Teori, praktik \\
\hline $09.00-10.00$ & $\begin{array}{l}\text { Penyusunan prosedur tanggap darurat } \\
\text { bencana di sekolah }\end{array}$ & Praktik \\
\hline $10.00-11.30$ & Pembuatan jalur, rambu, dan peta evakuasi & Praktik \\
\hline $11.30-12.00$ & Ishoma & \\
\hline $12.00-14.00$ & Simulasi evakuasi & Praktik \\
\hline $14.00-14.30$ & Evaluasi kegiatan & Praktik \\
\hline $14.30-15.30$ & Rencana Tindak Lanjut & \\
\hline $15.30-16.00$ & Penutupan & \\
\hline
\end{tabular}

\section{HASIL, PEMBAHASAN, DAN DAMPAK}

Pelatihan diikuti oleh siswa dan guru sekolah SD Muhammadiyah se-Kecamatan Banguntapan, Bantul, yaitu SD Muhammadiyah Banguntapan, SD Muhamamdiyah Kalangan, SD Muhammadiyah Bodon, SD Muhammadiyah Karang bendo, SD Muhammadiyah Mertosanan, dan SD Muhammadiyah Karang turi. Masing-masing SD 
Diterbitkan oleh Lembaga Pengabdian kepada Masyarakat

Universitas Ahmad Dahlan Yogyakarta

mengirimkan empat siswa dan satu orang guru untuk mengikuti pelatihan ini, sehingga target peserta tercapai yaitu 30 peserta.

peserta diperkenalkan dengan lagu anak siaga bencana. Peserta dan fasilitator bersama-sama menyanyikan lagu tersebut. Lagu ini termasuk dalam kategori lagu anakanak, sehingga baik lirik dan gambarnya pun sesuai dengan karakteristik anak-anak yaitu ceria, penuh gambar dan animasi, dan mudah untuk dihafal serta dinyanyikan. Ketika pelaksanaan kegiatan, lagu ini digunakan untuk ice breaking selain menggunakan metode permainan.

Selanjutnya, peserta diberikan materi berupa teori dan studi kasus terkait kebencanaan. Hal ini dimaksudkan untuk menunjang pengetahuan peserta terkait bencana. Studi kasus diberikan agar peserta mampu memahami, mendeteksi, dan menganalisis bencana yang ada disekitarnya. Adapun materi yang diberikan adalah : (1) Sekolah Aman Bencana (2) Analisis Bencana (3) Kajian risiko Bencana di sekolah (4) Pembuatan peta sekolah. Materi 1 dan 2 disampaikan oleh Khoiriyah Isni, S.K.M.,M.Kes dan materi 3 dan 4 disampaikan oleh Oktomi Wijaya, S.K.M.,M.Sc.

Peserta diberikan waktu untuk melihat film terkait bencana, setelahnya fasilitator memberikan pertanyaan terkait bencana yang terdapat dalam video atau film yang diputar. Hal ini dimaksudkan untuk mengetahui tingkat pemahaman peserta kaitannya dengan materi yang telah disampaikan.

Kegiatan selanjutnya adalah peserta diminta untuk berkelompok dan berdiskusi untuk mengkaji risiko-risiko bencana yang kemungkinan terjadi di sekolah. Hasil diskusi masing-masing kelompok dituliskan dikertas plano yang telah disediakan dan siswa diminta untuk mempresentasikan hasil diskusi kelompoknya di depan kelas. Setelah peserta paham terkait bencana, analisis dan kajian risiko bencana di sekolah, maka fasilitator memberikan instruksi untuk membuat peta sekolah masing-masing di kertas plano yang telah disediakan. Hal ini bertujuan agar warga sekolah benar-benar paham terkait kondisi dan tata letak sekolah masing-masing ketika menghadapi bencana. Seluruh rangkaian kegiatan yang dilakukan oleh siswa, didampingi oleh guru dari sekolah masing-masing. Harapannya adalah pemahaman terkait bencana dan penyusunan jalur evakuasi bancana ini tidak hanya diketahui dan dipahami oleh siswa saja, namun juga dipahami oleh guru, sehingga dalam meletakkan jalur-jalur evakuasi dan alat-alat pencegahan bencana sesuai dengan standar nasional yang telah ditetapkan.

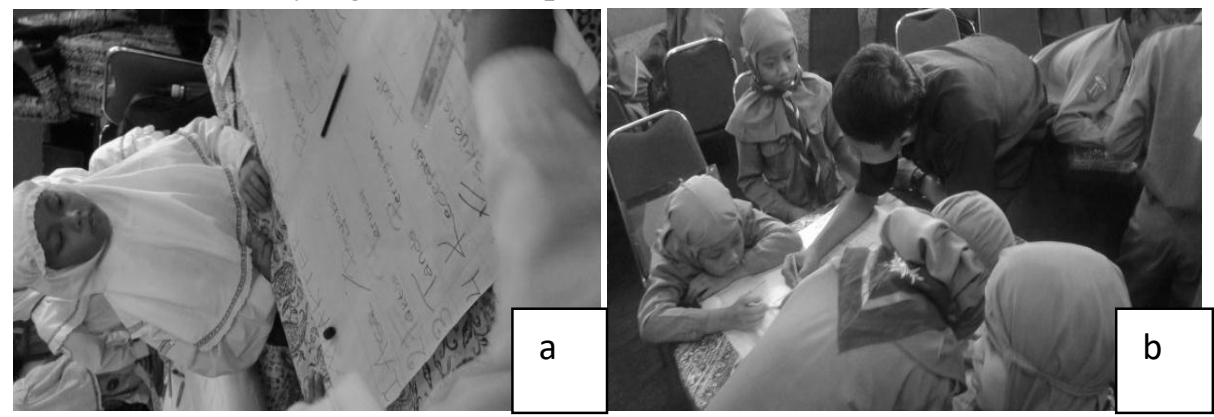

Gambar II. (a) Kajian analisis dan risiko bencana di sekolah, (b) Penyusunan peta dan jalur evakuasi didampingi oleh guru 
Pelatihan atau praktik yang dilakukan meliputi : (1) Penyusunan rencana evakuasi sekolah, (2) Penyusunan prosedur tanggap darurat bencana di sekolah, (3) Pembuatan jalur, rambu, dan peta evakuasi bencana di sekolah, (4) Simulasi evakuasi bencana di sekolah. peserta diminta untuk membuat rencana evakuasi bencana sesuai dengan kondisi sekolah masing-masing. Peserta harus dapat mengidentifikasi lokasi-lokasi untuk dijadikan titik kumpul ketika ada bencana mungkin terjadi di sekolah masing-masing. Idealnya, titik kumpul adalah tempat dimana semua warga sekolah dapat berkumpul menjadi satu dan tidak ada ancaman bahaya ketika bencana datang, seperti lapangan upacara sekolah.

Praktek penyusunan prosedur tanggap darurat sekaligus pembuatan jalur dan rambu evakuasi bencana di sekolah. Siswa diminta untuk membuat tanda jalur evakuasi bencana pada peta sekolah yang dibuat pada hari pertama. Pembuatan jalur evakuasi pada peta menggunakan spidol warna yang berbeda-beda dengan didampingi oleh guru masingmasing. Antusiasme peserta pelatihan baik itu siswa maupun guru sangat terlihat, siswa bersemangat untuk membuat jalur evakuasi dengan dukungan dan pendampingan dari gurunya. Selanjutnya, siswa diminta untuk menempelkan rambu-rambu evakuasi yang telah disediakan oleh Tim PPM di SD Muhammadiyah Bodon, sebagai percontohan pemasangan yang benar untuk rambu-rambu evakuasi bencana di sekolah. Sehingga setelah peserta mengikuti pelatihan, harapannya rambu-rambu tersebut dapat dipasang di sekolah masing-maisng dengan benar dan sesuai.

Simulasi dilakukan dengan pemberian skenario bencana pada suatu sekolah, dan bermain peran (role play) untuk memainkan peran ketika ada bencana yang terjadi saat sedang di sekolah. Evaluasi kegiatan dilakukan dengan memberikan pre test dan post test mengenai kebencanaan untuk siswa. Adapun hasil pre-test dan post test adalah sebagai berikut:

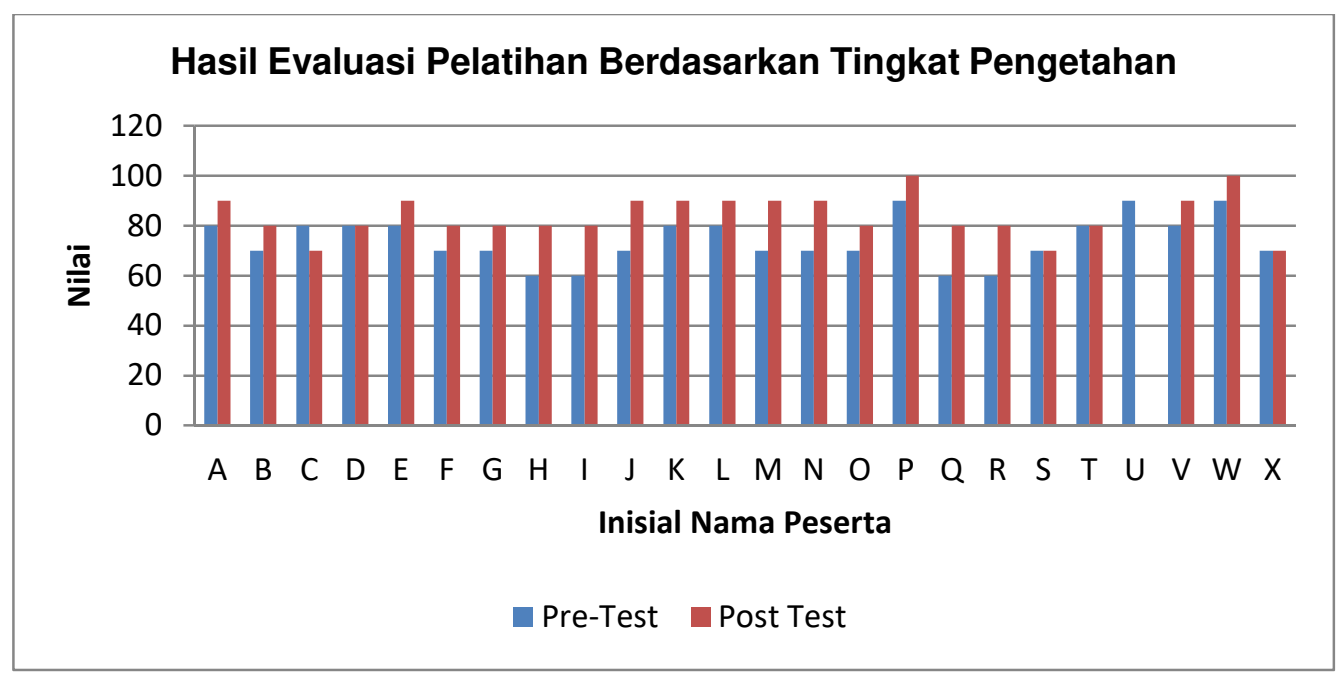

Berdasarkan tabel tersebut, dapat diketahui jumlah siswa yang mengikuti pre test sebanyak 24 siswa dengan nilai rata-rata 74,16. Sedangkan siswa yang mengikuti post test sebanyak 23 siswa dengan nilai rata-rata 80.41. Dari hasil tersebut, secara umum pelatihan penyusunan rencana evakuasi bencana di sekolah SD Muhammadiyah se-Kecamatan Banguntapan dapat dikatakan ektif dalam meningkatkan pengetahuan dan sikap siswa sekolah dasar terkait kebencanaan. Walaupun demikian, perlu dicermati kembali, bahwa 
Diterbitkan oleh Lembaga Pengabdian kepada Masyarakat

Universitas Ahmad Dahlan Yogyakarta

terdapat 1 siswa yang memiliki nilai pre test lebih tinggi daripada nilai post test, serta 4 siswa yang menunjukkan tidak adanya perubahan nilai pre test dan post test. Hal ini mungkin saja terjadi dikarenakan berbagai macam faktor, salah satunya kurang konsentrasi dalam pengerjaan post test atau siswa SD cenderung menjawab soal yang sama dengan jawaban yang sama. Sehingga ke depannya hal ini dapat menjadi masukan bagi akademisi baik dari perguruan tinggi maupun dari sekolah masing-masing. Pemberian training atau pelatihan dapat meningkatkan pengetahuan siswa di sekolah dasar, hasil yang diperoleh pada pelatihan bencana di SD Muhammadiyah banguntapan juga sejalan dengan penelitian Septiadi (2012), yang menunujukkan adanya peningkatan pengetahun siswa SD Sang Timur Semarang tentang tanggap darurat bencana setelah dilakuka intervensi dengan cara memberikan pre test dan post test. Selain dengan pelatihan, peningkatan pengetahuan bencana dapat dilakkan dengan mengintegrasikan model pembelajaran terpadu materi pengurangan risiko bencana dalam materi pelajaran. Hasil penelitian Pembriati dkk (2013) menunjukkan bahwa model pembelajaran terpadu tentang pengurangan risiko bencana sangat efektif dalam meningkatkan pengetahuan siswa tentang bencana.

\section{KESIMPULAN}

Berdasarkan hasil kegiatan yang telah dilaksanakan, maka dapat disimpulkan beberapa hal sebagai berikut:

1. Target capaian peserta pelatihan telah terpenuhi, yaitu 30 orang, terdiri dari 24 siswa dan 6 guru SD Muhammadiyah se-Kecamatan Banguntapan.

2. Kegiatan pelatihan efektif dalam meningkatkan pengatahuan dan sikap siswa SD terkait kebencanaan sekolah. Terbukti dari 24 siswa, sebanyak 19 siswa yang menunjukkan peningkatan nilai pre test dan post test. Rerata pre test sebesar 74.16 dan rerata post test sebesar 80.41 .

3. Tersusunnya peta, jalur, dan rambu evakuasi bencana sesuai dengan lokasi, situasi, dan kondisi sekolah masing-masing.

\section{DAFTAR PUSTAKA}

Badan Perencanaan Pembangunan Nasional, 2007, Peluncuran Buku Rencana Aksi Nasional Pengurangan Resiko Bencana Tahun 2006-2009. Jakarta : Bappenas.

Karnawati D Pramumijoyo S, Husein S, Andayani B, \& Burton PW, 2010, Development of community based earthquake hazard mapping - A pilot study in Bantul, Yogyakarta Province, Indonesia. In IRP-ADRC, Recovery Status Report No. 01 The Yogyakarta and Central Java Eathquake 2006, 2009 pp.67-80

Kementerian Pendidikan dan Kebudayaan Republik Indonesia. 2017. Apa itu Sekolah/Madrasah Aman Bencana. http://smab.kemdikbud.go.id/page/tentang, diakses pada tanggal 10 Februari 2017.

Pembriati, Zohrian Erly, Santosa S, Sarwono, 2013, Pengaruh Model Pembelajaran

Terpaduu Pada Pengintegrasian Materi Pengurangan Risiko Bencana Dalam Mata 
Pelajaran IPS SMP Terhadap Pengetahuan dan Kesiapsiagaan Bencana, Jurnal Bumi Lestari, Vo.1, No.1, hal. 1-8

Septiadi, anas, 2012, Perbedaan Sistem dan Pengetahuan Tanggap Darurat Bencana Kebakaran Sebelum dan Sesudah Pemberian Pelatihan Pada Gedung Sekolah Dasar Sang Timur Semarang, Jurnal Kesehatan Masyarakat FKM Undip Vol.1 No.2 halaman 635-643. 